\title{
Physiotherapy students' conceptualisations of clinical communication: A call to revisit communication in physiotherapy education
}

\author{
Felicity AS Bright ${ }^{1}$, Christine Cummins ${ }^{1}$, Kate Waterworth ${ }^{2}$, Barbara E Gibson ${ }^{3}$, Peter Larmer ${ }^{4}$
}

1. Centre for Person Centred Research, Auckland University of Technology, Auckland, New Zealand

2. Department of Physiotherapy, Auckland University of Technology, Auckland, New Zealand

3. Bloorview Research Institute in the Critical Disability and Rehabilitation Studies, Bloorview Research Institute, Holland Bloorview Kids Rehabilitation Hospital, Toronto and Department of Physiotherapy, University of Toronto, Toronto, Canada

4. School of Clinical Sciences, Auckland University of Technology, Auckland, New Zealand

Submitted: 18 May 2018 | Accepted: 19 December 2018 | DOI: 10.14426/art/509

\begin{abstract}
Background: Communication is fundamental in collaborative physiotherapy practice. Students develop understandings of what constitutes 'good' communication through the formal, informal and hidden curricula. Understanding how students understand communication and how this is influenced by the curricula can help educators consider how best to enhance communication knowledge and skills. Aim: This study explored how physiotherapy students conceptualised clinical communication. Methods: This study was underpinned by a social constructionist epistemology. Data consisted of fifteen assignments, completed by students as part of their coursework. Assignments were analysed using the Listening Guide which prompted attention to how the different ways students understood communication and how these understandings were constructed. Results: Communication was understood as uni-dimensional. It was presented as an act done to the patient by the physiotherapist, with little attention to the patient's communication and involvement in the interaction. Through communication, physiotherapists demonstrated and reinforced their expertise while simultaneously positioning the patient as the recipient of care and knowledge. Conclusion: Understandings of communication reflect broader constructions of physiotherapy and the role of the physiotherapist. These also reflect tensions in the curricula. Enhancing communication in student education requires all parties to understand, value and critically reflect on how communication is constructed and enacted.
\end{abstract}

Keywords: communication, curriculum

Copyright: This work is licensed under a Creative Commons Attribution 4.o International License.

\section{Introduction}

Clinical communication is considered a core competency in physiotherapy practice, and is prioritised within professional standards and legislative requirements (e.g. Physiotherapy Board of Australia and Physiotherapy Board of New Zealand, 2015). What constitutes 'good' and 'effective' clinical communication is less clear. In physiotherapy, communication is commonly focused on ascertaining information, making a diagnosis, conveying an 'appropriate' treatment plan, and providing patient education (Hiller, Guillemin, \& Delany, 2015). Such a task-focused approach is often dominated by the therapist (Roberts \& Bucksey, 2007) and may focus on the patient's impairment, with less attention to the patient's emotions, experiences, and context (Hiller \& Delany, 2018). This approach, which some have labelled 'transactional' (Bright, Kayes, McPherson, \& Worrall, 2018) or 'practitioner-centric' (Hiller et al., 2015), places the therapist in control of the interaction, determining what is discussed, known and done, and reflects dominant biomedical models of

\section{Corresponding author}

Felicity Bright (felicity.bright@aut.ac.nz)

ORCID: https://orcid.org/oooo-0002-8522-8287

Centre for Person Centred Research, Auckland University of Technology, Auckland, New Zealand physiotherapy practice (Nicholls \& Gibson, 2010). The structured, repeatable nature of interactions may reflect the clinical reasoning process employed by therapists (Hiller \& Delany, 2018), which may further reinforce the task-centred nature of the interaction.

The characteristics of the transactional or practitioner-centred approach contrast with those said to represent expert

physiotherapy communication (Jensen, Gwyer, Shepard, \& Hack, 2000; King et al., 2007). 'Expert' communication in physiotherapy is said to be evident through dynamic, responsive interactions which are sensitive to patients' emotions and their broader contexts and priorities (Jensen et al., 2000; King et al., 2007). Such interactions are characterised by a focus on the patient's needs and perspectives, seeking the patient's narrative and experiences, active patient participation, and active listening by the physiotherapist (Bright, 2016; Hiller et al., 2015). Such communication, which some describe as 'person-centred' (Hiller et al., 2015; Pinto et al., 2012) is 
associated with positive patient experiences and outcomes of therapy (Jensen et al., 2000; Pinto et al., 2012). It is not uncommon for physiotherapists to employ both 'practitioner-centred' and 'patient-centred' communication within a clinical interaction, each for different purposes (Hiller et al., 2015). This suggests that clinical communication requires the physiotherapist to adapt their communication style depending on the purpose of the interaction and the needs of the patient - a complex, nuanced, skilled way of working (Salmon \& Young, 2011).

While communication is valued in physiotherapy, there has been limited research exploring how communication is addressed in physiotherapy training, or how physiotherapy students (or their supervisors) understand and enact communication. This contrasts with the amount of related research in other health disciplines such as medicine and dentistry (e.g. Carey, Madill, \& Manogue, 2010; Silverman, Kurtz, \& Draper, 2013). Student education is formative in developing professional identity and understandings of what it means to 'be' a physiotherapist and how to 'do' physiotherapy (Byng, Cairns, \& Duchan, 2002; Hafferty, 1998). Historically, physiotherapy education has taken a technical-rational approach (Schön, 1983), emphasising bioscientific theory, knowledge generation, and technical skills (Greenfield et al., 2015). Such an approach positions the physiotherapist as 'do-er to the patient' rather than 'do-er with the patient' (Nicholls \& Gibson, 2010) and may result in students thinking so-called 'softer skills' such as communication are of low priority and significance than objective, fact-based skills (Reynolds, 1996). The formal, informal and hidden curricula that students are taught and receive in their university education and while on clinical placements mediates how students understand and internalise what is considered competent practice; over time, these constructions come to be seen as 'natural' and obvious (Hafferty, 1998).

In this paper we explore how undergraduate physiotherapy students in Aotearoa/New Zealand understand communication. We come to this research taking the position that communication is inherently interactive and that meaning is co-constructed within the interaction between patient and physiotherapist. We also hold that the exclusive use of 'practitioner-centred' communication can be problematic in a person-centred way of working, consistent with the person-centred focus in national physiotherapy standards of practice (Physiotherapy Board of Australia and Physiotherapy Board of New Zealand, 2015).The aims of the study were: (a) to explore how students conceptualise 'good' clinical

communication in physiotherapy practice, and (b) to consider how these understandings may have developed. We analysed students' written reflections on practice experiences which were completed for summative assessment. Reflection is a core component in the learning process. Conscious reflection supports people to critique and evaluate their understandings, to learn from experience, to explore the impact of context, and make active choices about how they can work in the future (Boud, Keogh, \& Walker, 1985; Fook \& Gardner, 2007). We note that while reflection is valued in physiotherapy practice supporting both clinical and personal development, assessment of reflections is contentious because students actively construct their reflections to meet the purposes of assessment and are not necessarily an accurate representation of a student's thoughts and feelings (Sandars, 2009). While student assignments are cannot be assumed to reflect their actual communication skills (Parry \& Brown, 2009) and do not provide the full extent of their knowledge of communication, they do provide some insight into the students' "cognitive landscape" (Reynolds, 1996, p. 286) which may influence how they enact communication within their future physiotherapy practice. Additionally, the reflections can provide insight into how they interpret their lecturers' conceptualisations of communication (for example, responding to the learning outcome which requires them 'identify effective communication strategies'). Indeed, the process of being assessed, graded and receiving feedback can reinforce their understandings of communication. Importantly, developing insights into how these understandings arise can help educators consider how best to enhance communication knowledge and skills for future physiotherapy students and practitioners (Reynolds, 1996).

\section{Methodology and methods}

Using a social constructionist epistemology (Berger \& Luckmann, 1967), the study examined practitioner-patient communication, understanding it as an interactive social process that draws from, (re)produces and challenges dominant physiotherapy principles and practices. The social constructionist approach holds that knowledge is socially constructed through interaction and communication and is historically and culturally situated (Berger \& Luckmann, 1967). 'Reality' is not fixed and nor is it completely knowable; instead it is constructed and reconstructed through interaction (Berger \& Luckmann, 1967). We used the Voice Centred Relational Methodology (Bright, Kayes, Worrall, \& McPherson, 2018; Mauthner \& Doucet, 1998) a narrative approach which focuses on the different stories or perspectives within participants' narratives (or text or other data), recognising that people commonly hold multiple understandings of a situation or phenomenon. The analytic methods associated with the Voice Centred Relational Methodology are designed to help the researchers explore the different 'voices' (stories or perspectives), consider the relationships between these, and how these have come to be. The Listening Guide is the primary analytic tool. The Listening Guide involves a series of readings of the data, asking methodologically and theoretically informed questions to help the researcher/s explore the different perspectives within the data. The Listening Guide prompts the researcher to explore "What is happening here?" and "How is the person talking about themselves?" in the first two readings. The next two readings are determined by the epistemology, theoretical framework, and research question which underpin the study. This methodology prompted us to attend to the different ways students understand communication, and on how these understandings came to be. As a relational method, one which is commonly used to explore relationships between people and/or between concepts and ideas, this methodology was appropriate for this study of patient-physiotherapist communication. 


\section{Research context}

This study was completed in a single four year Bachelors' level physiotherapy programme in New Zealand. Approximately 80\% of students are under 24 years of age. Over $60 \%$ of students identify as women and the majority are European or Asian. The programme uses a range of teaching approaches including face-to-face lectures, small group tutorials, and online learning. Communication is a core clinical competency, embedded through the practice thresholds graduates are expected to meet. These thresholds include competencies such as "use clear, accurate, sensitive and effective communication to support the development of trust and rapport in professional relationships with the client and relevant others" and "deal effectively with actual and potential conflict in a proactive and constructive manner" (Physiotherapy Board of New Zealand, 2018). Communication is addressed within a range of papers within the programme, most explicitly in two papers: one in year one and one in year three, although was considered within other papers, often focusing on completing a subjective interview or providing education. This study utilised student coursework from the third-year university paper on professionalism in physiotherapy practice. The paper consisted of approximately 36 hours of lectures and tutorials and covered topics such as communication, ethics, consent, clinical reasoning, patient narratives, and professional values. It was intended to prompt students to think critically about practice and patient experiences, as well as develop knowledge of so-called 'soft skills' such as communication. The communication sessions addressed the importance of communication, communication challenges in physiotherapy, forms of communication such as touch, listening, negotiating, forms of clinical questioning, and tools for reflecting on communication including the Calgary-Cambridge model of communication (Kurtz \& Silverman, 1996) and the Global Consultation Rating Scale (Burt et al., 2014). There was no explicit pedagogical approach underpinning the teaching. During the course of the paper, students completed a compulsory two week apprenticeship (observation period in a physiotherapy department or practice), observing experienced practitioners and assisting them as they worked with patients. This was their first interaction with patients in the degree programme. Students were required to write a 3500 word reflection on their apprenticeship. This constituted the summative assessment for this paper.

\section{Recruitment and participants}

After receiving approval from the university's Ethics Committee, we invited approximately 45 fourth year physiotherapy students to participate in this study. These students were identified through convenience sampling (Tracy, 2013); they were all on placement within a confined geographical area close to the research location. Students had completed the paper at least four months prior to recruitment and had received their final grade for the course. One researcher met the students to explain the study. Students were invited to contact the researcher if they wished to participate. Fifteen physiotherapy students (four men, eleven women) consented to sharing the specified written course assignment with the researchers. Beyond gender, we have no other demographic information, nor do have the final mark they received for their assignment. As two of the authors taught in the physiotherapy programme (KW and PL), several steps were taken to ensure they could not identify participants: (1) participant information and raw assignments were only available to $\mathrm{FB}$ and $\mathrm{CC}$; (2) the assignments were anonymised by one author (FB) before analysis by FB, CC and KW; and (3) assignments were assigned an alphanumeric identifier.

\section{Data}

Data consisted of 15 written student assignments completed in their previous year of study. Each assignment was approximately 3500 words. Within the assignment, students were required to reflect on and analyse a number of practice elements including: the roles and responsibilities of physiotherapists in interdisciplinary teams; communication and effective communication strategies; the application of the national codes of rights; and the complexities of practice. The learning outcome relating to communication required students to identify and analyse communication techniques, methods and purposes and demonstrate an understanding of the components of effective communication. The full learning outcome and marking grid are provided in Appendix 1. Each assignment was considered a 'text' and assigned a number. These numbers are used throughout the Findings when raw data from the text is provided to support and illustrate the analysis.

\section{Data analysis}

The Listening Guide was used to facilitate analysis (Bright, Kayes, Worrall, et al., 2018; Gilligan, Spencer, Weinberg, \& Bertsch, 2003). The Listening Guide involves a series of four sequential readings of the data, asking methodologically and theoretically informed questions on each reading. For this study, the first reading considered 'What is happening here and what is my response as a researcher?' providing a broad overview of the content and reflexivity toward the researcher's position. The second reading asked 'How does the student speak of physiotherapy practice?'; the third asked 'How does the student speak of themselves?' while the fourth reading focused on 'How does the student speak of others (people or objects) and the relationships between themselves and others?'. Analysis was iterative. We initially analysed six assignments using the Listening Guide, seeking broad understandings of how students conceptualised physiotherapy practice. Once sensitised to this, we then returned to the data and analysed all 15 assignments to explore how students conceptualised communication, what they attended to and how they discussed it. Taking the position that communication is relational (Gergen, 2009) and that communication practices are socioculturally located (Shotter \& Gergen, 1994), we also explored how the students conceptualised the patient, the physiotherapist and physiotherapy practice. Constant comparison across assignments helped develop increasingly nuanced understandings of how students conceptualised communication, and how these conceptualisations were constructed. 


\section{Rigour}

Rigour was informed by Tracy's (2010) criteria for qualitative research. Actions to aid rigour included: analysing materials from multiple participants, using methodologically and theoretically informed robust analysis methods, joint analysis of initial transcripts and regular discussion amongst the research team. Our research team brought a range of expertise, including communication (FB), critical and sociological perspectives (BG, $\mathrm{CC}, \mathrm{KW}$ ), and physiotherapy education (KW, BG and PL). Reflexivity was aided through the use of the Listening Guide and the explicit question 'what is my response as researcher?' and the research team discussions.

\section{Findings}

Communication was primarily presented as unidimensional and unidirectional, an act completed or accomplished by the physiotherapist as stated in one assignment: "[the supervisor] performed a subjective interview" (Text 2). Communication was commonly described as something done to the patient, with the act of communication and its accomplishment/s attributed to the physiotherapist. Examples of this included: "I was able to educate and portray my role to my patients. This helped to ensure clarity between me and the patient" (Text 5), and "When interpreters were available, the physiotherapists were able to communicate effectively to their patients" (Text 14). Across the data set, the physiotherapist was considered responsible for successful communication, with some assignments arguing this was a hallmark of expert practice: "I came to a realisation that verbal communication is not based on just the idea of 'speaking'; it is a broad term that is an extremely essential asset to being a great physiotherapist” (Text 8).

Communication was described as important for developing rapport and trust. Notably, the subjective interview was commonly described as the primary opportunity for establishing rapport. This implies relationships were considered important, but that they were important for particular purposes, namely, as a conduit to enhance 'motivation' and adherence to physiotherapy recommendations, or as a mechanism to improve the transference of information via 'patient education'.

Relationships were not seen as outcomes in themselves nor as a means to construct a collaborative partnership between therapist and patient, as advanced in literature on therapeutic relationships (e.g. Besley, Kayes, \& McPherson, 2011; Miciak, Mayan, Brown, Joyce, \& Gross, 2018). Rather rapport was a means to an end, and that end was more often than not related to securing compliance. As an example, one assignment described this, saying: "through this questioning, good rapport is being built and the patient will become more open, enabling treatment to run more smoothly" (Text 5).

Conceptualising communication and relationships as something 'done by' the physiotherapist contrasts with models which position communication as co-constructed, achieved through joint action, and achieved through relationships (e.g. Gergen, 2009). At times, patients were described as "receivers" of the therapist's verbal communication (Text 8). There was a notable absence of attention to the patient, to dialogue, how it was co-constructed between the patient and physiotherapist, and how the physiotherapist's communication was received, interpreted, and/or acted on by the patient. This absence suggests a relationship in which the physiotherapist dominated and the patient supplied the required information and actions when required.

Communication provided an avenue for showing and sharing physiotherapy expertise, evident in phrases such as "delivering education", "prescribing exercise" and "enlightening the patient". Co-occurring discussions about patients focused on their diagnoses and impairments, positioning them as impaired bodies which needed to be treated through physiotherapists' expert knowledge. Communication was presented as a mechanism through which physiotherapists demonstrated and reinforced their knowledge while simultaneously positioning the patient as a passive recipient of care and information, subject to the acts and putative expertise of the physiotherapist. For example, one assignment suggested "understanding the patient's perspective made them more compliant to physiotherapy input and was very effective in goal planning" (Text 1). Underpinning these constructions of communication were assumptions that the physiotherapist's communication activities and resulting patient 'compliance' would result in improved functional and impairment-related outcomes.

The therapist's position of expert was bolstered through their use and control of textual information about the patient. Subjective information was seen to be verified in a process of triangulation with the information written in the clinical notes. Some assignments suggested these notes were considered a more reliable and authoritative communicator than the patient themselves in many instances, with one stating:

"After introducing herself and explaining the
assessment, [the supervisor] began recounting some
of the information she had gathered through the
patient's notes. Recounting past medical history,
diagnosis, medications and allergies allowed her to
ensure her notes were correct and gauge the patient's
awareness of their medical history (Text 6)."

Documentation such as structured clinical assessments forms also acted as an influence on communication practices as evidenced in one assignment: "Prewritten cardiac and pulmonary assessment templates are used to guide the interview" (Text 3), suggesting that particular forms of knowledge are considered desirable by the profession or healthcare institution and may determine what is considered legitimate knowledge.

The assignments suggested that the students' abilities to reflect on the nuances of communication were influenced by their undergraduate physiotherapy education and the rhetoric and logics in which they had been trained. For instance, within assignments, there was limited description of what constituted 'good communication'. Instead written reflections drew on clinical terms and outcomes with communication classed as "effective" or "ineffective". Other assignments drew on different classification systems taught within the first and third years of 
physiotherapy education: "Most physiotherapists had attentive and friendly styles while nurses appeared to have contentious and dominant styles" (Text 11). Beyond this, there was rarely any description or nuanced analysis of communication, why it occurred in that way, and/or what it brought about.

Communication modalities such as touch, silence, and other forms of nonverbal communication were missing in the reflections. It should be noted that the students had completed one course on the nature of touch, which included discussions of touch as a communication modality. Overall, the reflections suggest students' narrow understandings of communication are shaped by the curricula to which they are exposed, including both overt instruction and all the cues they internalise regarding their roles as experts.

A number of assignments critiqued broader systemic issues as having significant influence on physiotherapy practices and service provision. One directly asked: "how can we provide this optimum treatment if we are limited by timeframes tailored to a business model" (Text 2) while another suggested "the treatment is so focused on the ultimate goal of having the patient discharged as quickly as possible" (Text 10). The assignments indicated that resource and policy restrictions impacted on the communication practices of physiotherapists:

"In order to see the number of patients needing help in two acute care wards, the communication had to be therapist-centred. My therapist allowed patients to express themselves, however within the bounds of a structured framework of conversation" (Text 1).

Although this example seems somewhat unquestioning of the restrictions on practice, other assignments demonstrated a greater attempt to explore the disjunction between their classroom learning and complex practice experiences. Many made reference to the change from a historical notion of a physiotherapist relying on an understanding of the body-as-a-machine to a practitioner more comfortable with a psychosocial model and person-centred care. Despite this, the reflections evident in the assignments did not suggest a substantive philosophical shift. Nor did they extend to higher levels of critique of physiotherapy practice or physiotherapy education itself. One student highlighted "[learning institution] teaches subjective interviews in a very structured manner which my supervisor was following to ensure all 'necessary information' was obtained” (Text 1) however did not further unpack this nor how this informed their own (and dominant) understandings of physiotherapy and communication practices. This may suggest that the physiotherapy curricula explicitly conveys the message that there are certain fixed procedures that students and practitioners should follow, while implicitly suggesting that such procedures are beyond criticism.

\section{Discussion}

Our findings suggest both physiotherapy practice and clinical communication as something 'done to' the client by the expert physiotherapist. The formal, informal and hidden curricula that students are taught and receive in their university education can influence how students understand what is considered 'appropriate' communication (Reynolds, 1996; Rosenbaum \& Axelson, 2013). Accordingly, we argue that critically attending to communication teaching in student education is vitally important. Moreover, we suggest communication needs to be understood in relation to the dominant understandings of practice that persist in positioning clinicians as knowledge providers and patients as passive receivers of 'education' and instruction. The student reflections demonstrated how, through communication, the physiotherapist is constructed as the expert practitioner who 'does' physiotherapy to the passive recipient of care. This 'patient' is both object of care and (potentially unreliable) subjective reporter of his/her bodily impairments. Such understandings are socioculturally located, influenced by a healthcare system which values efficiency and effectiveness, the physiotherapy profession which relies on status as an important component of professional identity, and the education system which trains students to 'do' physiotherapy and values particular aspects of communication.

Communication was commonly constructed as mechanistic, reminiscent of the 'body-as-machine' discourse which underpins the historical roots of the profession (Nicholls, 2018; Nicholls \& Gibson, 2010). Communication was considered to have a specific function, completed for the purposes of assessment, diagnosis and treatment. The patient was constructed primarily as the object/target of the episode of care rather than a person/partner in an interactive process. This objectification process was amplified by the students' lack of attention to the context of the interaction, to the patient's actions within the communication episode and to the patient's life context, priorities or incidental information. In turn, this may reflect the relative priority and the particular understandings of communication contained within the formal, informal and hidden physiotherapy curricula to which the students had been exposed. We should reiterate that our claim is not that communication and interpersonal skills are not valued by those who (re)produce the curricula. We concur with Nicholls (2018) who identified these were reflected in the capabilities physiotherapy supervisors required students to demonstrate on their placements. It may be that this is further evidence of the tensions in both the curricula and the profession, which is rooted in mechanistic approaches but also acknowledges, perhaps inconsistently, the human aspects of care (Setchell et al., 2017), with Nicholls (2018) arguing that 'it was assumed that the physiotherapist would learn to be enabling, creative and cognisant of power imbalances despite their curriculum rather than because of it” (p. 213).

The 'subjective interview' was constructed as a key site for communication between the physiotherapist and the patient, even while being considered a precursor to the 'real work' of physiotherapy itself. The physiotherapist was said to use certain communication strategies during the 'subjective interview' in order to reveal clear, concrete and detailed information about the patient to further assess through objective assessment and diagnostic procedures. The 'subjective interview' also acted to cement the physiotherapist as expert provider of information and 'truth'. Communication practices in the 'subjective interview' therefore act to objectify the patient - with persons 
being made into knowable patients through these processes - as objects in the sense of their impairments and as subjects only insofar as their function to provide needed information. This process may be reinforced by institutional practices designed to promote adherence to legal standards and mitigate risk such as the use of templates to guide interviews and record information. Viewing clinical records as the legitimate record of interactions (Mathioudakis, Rousalova, Gagnat, Saad, \& Hardavella, 2016), admissible in court, may further objectify the patient and reinforce the assumed expertise of the physiotherapist as the objective, reliable observer. It is interesting to reflect on this positioning in light of patients being increasingly informed and knowledgeable about their health conditions, with the 'expert' status of the practitioner being contested but also resisted (Greenhalgh, Snow, Ryan, Rees, \& Salisbury, 2015; Koch, Jenkin, \& Kralik, 2004).

This research utilised student coursework, produced for the purposes of assessment. It also drew solely on student reflections on their supervisors' communication over a two week apprenticeship, clearly only a limited exposure to practice. Additionally, the very nature of the assignment (including the wording of the learning outcome and the marking criteria) structured what students addressed in their reflections. In writing for assessment, students produced material that they considered will be met with approval by teaching staff (Thompson, 2001); they also reproduced what they have learned from staff - often the same staff. This is notable given that assignments focused on physiotherapists' verbal communication, not patient communication, despite the latter being explicitly mentioned in the marking criteria for the assignment. This suggests students considered these were the aspects of communication expected and valued by teaching staff and demonstrates a possible mismatch between the formal, informal and hidden curricula (Hafferty, 1998); what students have come to understand is important in communication. While we recognise the limitations of using written reflections as means of exploring students' understandings, and that other methods might provide different insights into their understandings of communication and/or student communication skills, the written reflections provided some detailed information about their interpretations of 'good' communication, their communication priorities, and provides useful starting point for those interested in enhancing the communication curricula in physiotherapy.

This research raises questions about what physiotherapy curricula do and the unintended consequences of current approaches to communication teaching. Teaching methods vary but the lecture style remains a prominent approach for teaching communication (and other topics) (Nicholls, 2018) with students often expected to make their own links between this and their clinical practice experience (Parry \& Brown, 2009). However experiential learning is likely to be enhanced with active clinical education, formative feedback of and observational assessment on communication practices (Kurtz, Silverman, \& Draper, 2005). Teaching communication as transactional and unidirectional, focused on information-gathering and information-giving, leads to particular understandings and reflections on communication and on physiotherapy practice more broadly. Consistent with our findings, Reynolds (1996) noted that physiotherapy students participating in an interprofessional programme appeared to struggle to notice and 'respond' to patient's emotions. This highlights the need for educators to critically consider how assessment and curricula can (re)produce and reinforce the physiotherapist's position as expert while subjugating the knowledge and expertise of patients. Our findings suggest a tension in the curriculum, between educating students to 'do to' their clients, while also seeking to develop their skills as collaborative, person-centred practitioners. We suggest that if students are to develop collaborative person-centred physiotherapy practices, this requires greater, and arguably more explicit attention within education and physiotherapy pedagogical research.

Realising a shift in practice requires not only a change in how communication teaching is delivered but more fundamentally, a change in how the profession understands the purpose and effects of communication. Embedding this view within education requires a deep reflexivity not only on the part of students but also educators and practitioners to uncover their assumptions about the goals of each communication encounter, and skills in remaining open, humble and flexible in their approaches. Educators can be key to enforcing the status quo (Nicholls, 2018), and engaging them may be instrumental to embedding changes in the curricula. Anecdotally, some students report hearing messages such as 'that is all very well in theory but in practice this is what you need to do". This makes introducing new thinking very challenging. If students receive conflicting messages between classroom-based education and feedback in the practice contexts it will reinforce the tensions between formal, informal and hidden curricula.

Recommendations for teaching and learning thus must focus on acquiring knowledge and skills in critical reflexivity (Fook, 2010; Salmon \& Young, 2011) delivered by educators who are sensitive to their own and the profession's assumptions, biases and traditional modes of practice. However, it is recognized that these deeper levels of reflection can be difficult to achieve (Mann, Gordon, \& MacLeod, 2009). Landy et al. (2016) described varied and emergent teaching practices and strategies are used in health education to enhance students' critical reflexivity, from lecture and classroom-based to online, experiential and written activities such as journaling, although they also note that the pedagogy of critical reflexivity is varied and requires further development. We also suggest that close attention to the learning environment is crucial, as this can see reflexivity modeled and valued, or indeed, not (Mann et al., 2009). Enhancing reflexivity may be aided through the explicit teaching and use of reflective models, detailed exploration of critical incidents, and providing prolonged opportunities for deep reflection. Providing both authentic practice experiences, together with the support to reflect on these throughout the physiotherapy programme may be important for helping students to develop both their reflection skills, and to engage in a more comprehensive reflective process that allows them to translate knowledge from these reflections into their own practice (Mann et al., 2009). Physiotherapy has been slow to give explicit attention to what its practices produce, an important part of deeper reflection and critical reflexivity. We 
do note that the growing network of members in the Critical Physiotherapy Network (www.criticalphysio.net) indicates that many practitioners are interested in questioning individual and professional practices. Thus it may be appropriate timing to explore and unpack communication education and practices using a critical lens.

Embedding communication and person-centred aspects of care into the curricula is not without challenge (Nicholls, 2018), one that many professions are grappling with. Medicine is one profession which has made significant changes to ensure an explicit focus on communication in the context of a dominant biomedical orientation (Kurtz et al., 2005) and has produced consensus statements on communication in medical education. (Makoul \& Schofield, 1999; Noble, Scott-Smith, O'Neill, \& Salisbury, 2018). One approach is to incorporate humanities into the curricula (Bates, Bleakley, \& Goodman, 2014), often utilising narrative, art and other forms to prompt close attention to, and critical consideration of what it is to be human, informing understandings of the patient experience and the value of relationships (Shapiro, Coulehan, Dear, \& Montello, 2009). Requiring students to engage with families or service users, meeting and interviewing them regularly over the course of a year or longer, to develop deep understandings of development and experiences of health service may help them attune to the processes of communication in developing and maintaining relationships (Blaylock, 2000; Johnson, Yoder, \& Richardson-Nassif, 2006). Simulated patients are commonly used in clinical teaching in a number of contexts and provide explicit opportunities for students to develop and reflect on both their technical skills and their communication and relational skills (MacLean, Kelly, Geddes, \& Della, 2017). Interdisciplinary teaching teams, incorporating staff with communication expertise (often from outside the discipline) may bring different perspectives and strong theoretical and practical knowledge to support staff and students (Woodward-Kron, Stevens, \& Flynn, 2011). These are just four examples of strategies which might support students to develop a more critical, creative understanding of healthcare communication (Salmon \& Young, 2011).

We acknowledge, however, the complexities of changing curricula, even in the context of supportive management structures. It may be that a significant change in education models is required to truly see communication inherently valued and well-addressed within physiotherapy education (Nicholls, 2018). We also note that physiotherapy is in a time of significant change. Its future direction is being discussed (Nicholls, 2018). Communication modalities and capabilities are changing as technology is increasingly used in clinical practice (Noble et al., 2018). This context provides exciting opportunities for educators to critically consider what communication may look like in future practice, and what competencies and capabilities are required to support students to be skilled, critical and creative communicators in $21^{\text {st }}$ century physiotherapy practice (e.g. Brunner et al., 2018). If teaching is informed by a future-oriented perspective, we also need to consider what supports educators require. Students may go on placement and observe more 'traditional' approaches to communication which may limit the possible impact of a future-oriented pedagogy. This is another reason why engaging with educators may be just as critical as engaging with students. Enhancing knowledge and mindfulness of communication and relational work within student education requires all parties to understand and value all the ever-moving strands in the "web of practices" which constitute collaborative person-centred physiotherapy practices.

\section{Acknowledgements}

This research was funded by an Auckland University of Technology School of Clinical Sciences Early Career Researcher Grant (FB). We thank the participants for sharing their work with us.

\section{References}

Bates, V., Bleakley, A., \& Goodman, S. (Eds.). (2014). Medicine, health and the arts: Approaches to the medical humanities. London, United Kingdom: Routledge.

Berger, P. L., \& Luckmann, T. (1967). The social construction of reality: A treatise in the sociology of knowledge. New York: Anchor Books.

Besley, J., Kayes, N. M., \& McPherson, K. M. (2011). Assessing therapeutic relationships in physiotherapy: Literature review. New Zealand Journal of Physiotherapy, 39(2), 81-91.

Blaylock, B. L. (2000). Patients and families as teachers: Inspiring an empathetic connection. Families, Systems \& Health, 18(2), 161-175. doi:10.1037/hoog1844.

Boud, D., Keogh, R., \& Walker, D. (1985). Promoting reflection in learning: A model. In D. Boud, R. Keogh, \& D. Walker (Eds.), Reflection: Turning experience into learning (pp. 18-40). Oxford, United Kingdom: Routledge.

Bright, F. A. S. (2016). Reconceptualising engagement: A relational practice with people experiencing communication disability after stroke. Auckland University of Technology, Auckland.

Bright, F. A. S., Kayes, N. M., McPherson, K. M., \& Worrall, L. E. (2018). Engaging people experiencing communication disability in stroke rehabilitation: A qualitative study. International Journal of Language and Communication Disorders, 53(5), 981-994. https://doi.org/10.1111/1460-6984.12409.

Bright, F. A. S., Kayes, N. M., Worrall, L., \& McPherson, K. M. (2018). Exploring relational engagement practices in stroke rehabilitation using the Voice Centred Relational Approach. International Journal of Social Research Methodology, 21(1), 35-48. doi:10.1080/13645579.2017.1316044. 
Brunner, M., McGregor, D., Keep, M., Janssen, A., Spallek, H., Quinn, D., ... Shaw, T. (2018). An eHealth Capabilities Framework for Graduates and Health Professionals: Mixed-Methods Study. Journal of Medical Internet Research, 2O(5), e10229. doi:10.2196/10229.

Burt, J., Abel, G., Elmore, N., Campbell, J., Roland, M., Benson, J., \& Silverman, J. (2014). Assessing communication quality of consultations in primary care: initial reliability of the Global Consultation Rating Scale, based on the Calgary-Cambridge Guide to the Medical Interview. BMJ Open, 4(3), 1-8. https://doi.org/10.1136/bmjopen-2013-004339.

Byng, S., Cairns, D., \& Duchan, J. F. (2002). Values in practice and practising values. Journal of Communication Disorders, 35(2), 89-106. doi:10.1916/Soo21-994(02)0o059-X.

Carey, J. A., Madill, A., \& Manogue, M. (2010). Communication skills in dental education: A systematic research review. European Journal of Dental Education, 14(2), 69-78. doi:10.1111/j.1600-0579.2009.00586.x.

Fook, J. (2010). Beyond reflective practice: Reworking the 'critical' in critical reflection. In H. Bradbury, N. Frost, S. Kilminster, \& M. Zukas (Eds.), Beyond reflective practice: New approaches to lifelong learning (pp. 37-51). Oxon, United Kingdom: Routledge.

Fook, J., \& Gardner, F. (2007). Practicing critical reflection: A resource handbook. Maidenhead, United Kingdom: Open University Press.

Gergen, K. J. (2009). Relational being: Beyond self and community. Oxford, United Kingdom: Oxford University Press.

Gilligan, C., Spencer, S. R., Weinberg, K. M., \& Bertsch, T. (2005). On the Listening Guide: A voice-centred relational method. In S. Hesse-Biber \& P. Leavy (Eds.), Emergent methods in social research (pp. 253-271). Thousand Oaks, CA: Sage.

Greenfield, B. H., Jensen, G., Delany, C. M., Mostrom, E., Knab, M., \& Jampel, A. (2015). Power and promise of narrative for advancing physical therapist education and practice. Physical Therapy, 95(6), 924-933. doi:10.2522/ptj.20140085.

Greenhalgh, T., Snow, R., Ryan, S., Rees, S., \& Salisbury, H. (2015). Six 'biases' against patients and carers in evidence-based medicine. BMC Medicine, 13(1), 200.

doi:10.1186/s12916-015-0437-x.

Hafferty, F. W. (1998). Beyond curriculum reform: Confronting medicine's hidden curriculum. Academic Medicine, 73(4), 403-407.

Hiller, A., \& Delany, C. (2018). Communication in physiotherapy: Challenging established theoretical approaches. In B. E. Gibson, D. A. Nicholls, J. Setchell, \& K. Synne Groven (Eds.), Manipulating practices: A critical physiotherapy reader (pp. 308-333).
Hiller, A., Guillemin, M., \& Delany, C. (2015). Exploring healthcare communication models in private physiotherapy practice. Patient Education and Counseling, 98(10), 1222-1228. doi:10.1016/j.pec.2015.07.029.

Jensen, G. M., Gwyer, J., Shepard, K. F., \& Hack, L. M. (2000). Expert practice in physical therapy. Physical Therapy, 8o(1), 28-43.

Johnson, A., Yoder, J., \& Richardson-Nassif, K. (2006). Using families as faculty in teaching medical students family-centered care: What are students learning? Teaching and Learning in Medicine, 18(3), 222-225. doi:10.1207/s15328015tlm1803_6.

King, G., Currie, M., Bartlett, D., Gilpin, M., Willoughby, C., Tucker, A., . . Baxter, D. (2007). The development of expertise in pediatric rehabilitation therapists: Changes in approach, self-knowledge, and use of enabling and customizing strategies. Developmental Neurorehabilitation, $10(3), 223-240$. doi:10.1080/17518420701302670.

Koch, T., Jenkin, P., \& Kralik, D. (2004). Chronic illness self-management: Locating the 'self'. Journal of Advanced Nursing, 48(5), 484-492. doi:10.1111/j.1365-2648.2004.03237.x

Kurtz, S. M., \& Silverman, J. D. (1996). The Calgary-Cambridge Referenced Observation Guides: an aid to defining the curriculum and organizing the teaching in communication training programmes. Medical Education, 3o(2), 83-89.

Kurtz, S., Silverman, J., \& Draper, J. (2005). Teaching and learning communication skills in medicine (2nd ed.). Oxford, United Kingdom: Radcliffe.

Landy, R., Cameron, C., Au, A., Camerson, D., O'Brien, K., Robrigado, K., ... Nixon, S. (2016). Education strategies to enhance reflexivity among clinicians and health professional students: A scoping study. Forum Qualitative Sozialforschung/Forum: Qualitative Social Research, 17(3). doi:10.17169/fqs-17.3.2573.

MacLean, S., Kelly, M., Geddes, F., \& Della, P. (2017). Use of simulated patients to develop communication skills in nursing education: An integrative review. Nurse Education Today, 48, 90-98. doi:10.1016/j.nedt.2016.09.018.

Makoul, G., \& Schofield, T. (1999). Communication teaching and assessment in medical education: An international consensus statement. Patient Education and Counseling, 37(2), 191-195. doi:10.1016/So738-3991(99)ooo23-3.

Mann, K., Gordon, J., \& MacLeod, A. (2009). Reflection and reflective practice in health professions education: A systematic review. Advances in Health Science Education, 14(4), 595-621. https://doi.org/10.1007/a1-459-007-9090-2.

Mathioudakis, A., Rousalova, I., Gagnat, A. A., Saad, N., \& Hardavella, G. (2016). How to keep good clinical records. Breathe, 12(4), 369-373. doi:10.1183/20734735.018016. 
Mauthner, N. S., \& Doucet, A. (1998). Reflections on a Voice-Centred Relational Method of data analysis: Analysing maternal and domestic voices. In J. Ribbens \& R. Edwards (Eds.), Feminist dilemmas in qualitative research: Private lies and public texts (pp. 119-144). London: Sage.

Miciak, M., Mayan, M., Brown, C., Joyce, A. S., \& Gross, D. P. (2018). The necessary conditions of engagement for the therapeutic relationship in physiotherapy: An interpretive description study. Archives of Physiotherapy, 8(3), 1-12. doi:10.1186/s40945-018-0044-1.

Nicholls, D. A. (2018). The End of Physiotherapy. Abingdon, United Kingdom: Routledge.

Nicholls, D. A., \& Gibson, B. E. (2010). The body and physiotherapy. Physiotherapy Theory and Practice, 26(8), 497-509. doi:10.3109/09593981003710316.

Noble, L., M., Scott-Smith, W., O'Neill, B., \& Salisbury, H. (2018). Consensus statement on an updated core communication curriculum for UK undergraduate medical education. Patient Education and Counseling, 1-8. doi:10.1016/i.oec.2018.04.013.

Parry, R. H., \& Brown, K. (2009). Teaching and learning communication skills in physiotherapy: What is done and how should it be done? Physiotherapy, 95(4), 294-301. doi:10.1016/j.physio.2009.05.003.

Physiotherapy Board of Australia and Physiotherapy Board of New Zealand. (2015). Physiotherapy practice thresholds in Australia \& Aotearoa New Zealand: Physiotherapy Board of Australia and Physiotherapy Board of New Zealand.

Physiotherapy Board of New Zealand. (2018). Physiotherapy Standards Framework. Wellington, New Zealand Physiotherapy Board of New Zealand.

Pinto, R. Z., Ferreira, M. L., Oliveira, V. C., Franco, M. R., Adams, R., Maher, C. G., \& Ferreira, P. H. (2012).

Patient-centred communication is associated with positive therapeutic alliance: A systematic review. Journal of

Physiotherapy, 58(2), 77-87.

doi:10.1016/S1836-9553(12)70087-5.

Reynolds, F. A. (1996). Evaluating the impact of an interprofessional communication course through essay content analysis: Do physiotherapy and occupational therapy students' essays place similar emphasis on responding skills? Journal of Interprofessional Care, 10(3), 285-295. doi:10.3109/13561829609034116.

Roberts, L., \& Bucksey, S. J. (2007). Communicating with patients: What happens in practice? Physical Therapy, 87(5), 586-594. doi:10.2522/ptj.20060077.

Rosenbaum, M. E., \& Axelson, R. (2013). Curricular disconnects in learning communication skills: What and how students learn about communication during clinical clerkships. Patient Education and Counseling, 91(1), 85-90.

doi:10.1016/j.pec.2012.10.011.

Salmon, P., \& Young, B. (2011). Creativity in clinical communication: From communication skills to skilled communication. Medical Education, 45, 217-226. doi:10.1111/j.1365-2923.2010.03801.x.

Sandars, J. (2009). The use of reflection in medical education: AMEE Guide No. 44. Medical Teacher, 31(8), 685-695. https://doi.org/10.1080/01421590903050374.

Schön, D. (1983). The reflective practitioner. New York, NY: Basic Books.

Setchell, J., Thille, P., Abrams, T., McAdam, L. C., Mistry, B., \& Gibson, B. E. (2017). Enhancing human aspects of care with young people with muscular dystrophy: Results from a participatory qualitative study with clinicians. Child: Care, Health and Development, 44(2), 269-277. doi:10.1111/cch.12526.

Shapiro, J., Coulehan, J., Dear, D., \& Montello, M. (2009). Medical humanities and their discontents: Definitions, critiques, and implications. Academic Medicine, 84(2), 192-198. doi:10.1097/ACM.obo13e3181938bca.

Shotter, J., \& Gergen, K. J. (1994). Social construction: Knowledge, self, others, and continuing the conversation. Annals of the International Communication Association, 17(1), 3-33. doi:10.1080/23808985.1994.11678873.

Silverman, J., Kurtz, S., \& Draper, J. (2013). Skills for communicating with patients (3rd ed.). London, United Kingdom: Taylor \& Francis Ltd.

Thompson, G. (2001). Interaction in academic writing: Learning to argue with the reader. Applied Linguistics, 22(1), 58-78. doi:10.103/aaplin/22.1.58.

Tracy, S. J. (2010). Qualitative quality: Eight "big-tent" criteria for excellent qualitative research. Qualitative Inquiry, 16(10), 837-851. doi:10.1177/1077800410383121.

Tracy, S. J. (2013). Qualitative research methods: Collecting evidence, crafting analysis, communicating impact. West Sussex, UK: Wiley-Blackwell.

Woodward-Kron, R., Stevens, M., \& Flynn, E. (2011). The medical educator, the discourse analyst, and the phonetician: A collaborative feedback methodology for clinical communication. Academic Medicine, 86(5), 565-570. doi:10.1097/ACM.obo13e318212feaf. 

education. OpenPhysio.

\section{Peer review reports}

Ronel Maart (rmaart@uwc.ac.za)

Reviewed: 27 September 2018

Citation: Maart, R. (2018). Review - Physiotherapy students' conceptualisations of clinical communication: A call to revisit communication in physiotherapy education. OpenPhysio. DOI: 10.14426/opj/20180927

Joost van Wijchen (joost.vanwijchen@han.nl)

Reviewed: 01 November 2018

Citation: Van Wijchen, J. (2018). Review - Physiotherapy

students' conceptualisations of clinical communication: A call to revisit communication in physiotherapy education. OpenPhysio. DOI: $10.14426 /$ opj/20181101

Veronika Schoeb (veronika.schoeb@hesav.ch)

Reviewed: 27 October 2018

Citation: Schoeb, V. (2018). Review - Physiotherapy students' conceptualisations of clinical communication: A call to revisit communication in physiotherapy education. OpenPhysio. DOI: 10.14426/opj/20181027 